\title{
Prognostic significance of CD44 expression in adenocarcinoma of the lung
}

\author{
M R Clarke, R J Landreneau, N M Resnick, R Crowley, G J Dougherty, D L Cooper, \\ $S$ A Yousem
}

\begin{abstract}
Aims-To determine whether expression of CD44 in neoplasia is associated with tumour grade, stage and prognosis.

Methods-The immunohistochemical expression of CD44 was evaluated using the mouse antihuman monoclonal antibody 3 G12 which recognises regions shared by all CD44 isoforms to determine whether expression in formalin fixed, paraffin wax embedded tissue correlates with tumour grade, stage or survival in adenocarcinoma of the lung. Thirty one adenocarcinomas of the lung, 16 T2N0 and 15 T2N1, and their nodal metastases were studied.
\end{abstract}

Results-Of the 31 tumours, 25 were positive for the CD44 antigen. CD44 expression correlated with tumour grade, in that intense staining was seen only in moderately and/or poorly differentiated tumours. CD44 did not correlate with nodal status, tumour size, pleural invasion, angiolymphatic invasion, or host inflammatory response, but did correlate with survival. A median survival of 46 months was observed in patients with moderate to strong CD44 expression compared with 24 months for those with no or weak expression. Nine patients were alive without evidence of disease at a median follow up of 61 months. Six (66\%) of these nine patients had strong CD44 expression. This contrasts with strong expression in only three (17\%) of the 17 patients dying with a median survival of 28 months.

Conclusion-In primary adenocarcinoma of the lung loss of CD44 expression is associated with less favorable outcome and may indicate a more aggressive neoplasm. CD44 may be a useful prognostic marker in lung carcinoma.

(f Clin Pathol: Mol Pathol 1995;48:M200-M204)

Keywords: CD44, adhesion molecule, lung cancer.

CD44 is a transmembrane glycoprotein with multiple biological functions including cellular adhesion. This molecule was originally recognised in lymphocytes and haematopoietic cells $^{12}$ and was shown to facilitate lymphocyte recirculation through adhesion to high endothelial venules ${ }^{34}$ and lymphocyte activation. ${ }^{56}$ The role of CD44 in cell-cell ${ }^{78}$ and cell-matrix binding has also been identified; CD44 is the principle cell surface receptor for hyaluronan and is also purported to be involved in adhesion to collagen, fibronectin and the cytoskeletal protein ankyrin. ${ }^{9-12}$ The CD44 molecule consists of a cytoplasmic portion, which may be involved in signal transduction, a transmembrane region and an extracellular component. The molecule is polymorphic and the gene, which has been mapped to the short arm of chromosome 11, encodes numerous isoforms, generated by molecular mechanisms of alternative splicing and post-translational modifications. ${ }^{13-15}$ The $80-90 \mathrm{kDa}$ isoform (CD44S) is expressed in haematopoietic cells and many other cell types ${ }^{16}$ and has been found to play a major role in tumour cell migration on hyalonate coated substrates. ${ }^{17} \mathrm{CD} 44 \mathrm{~S}$ also appears to play a role in tumour growth as demonstrated in studies by Sy et al ${ }^{18}$ in which lymphoma cells transfected with the CD44S isoform showed greatly enhanced local tumour formation when injected into nude mice. The larger, $140-160 \mathrm{kDa}$ epithelial isoforms (CD44R) are weakly expressed in normal epithelium and more strongly in carcinomas. ${ }^{19} \mathrm{~A}$ third class of CD44 isoforms encodes proteins of even larger size, the so-called "variant" isoforms (CD44v), expression of which, in certain rodent cell lines, has been found to confer metastatic potential to non-metastasising cell lines. ${ }^{2021}$ Homologous sequences of these variants were subsequently found in human carcinoma cell lines from lung, breast, colon, and pancreas. ${ }^{22}$ Recently, CD 44v expression was determined to be widely present throughout the body in benign tissues as well, principally in epithelial cells, and to be modulated by cytokines. ${ }^{23}$

In studies on human breast and colon carcinomas, variant isoforms are preferentially expressed in neoplastic tissues compared with normal tissues. ${ }^{24-27}$ Associations have also been found between tumour stage and prognosis and variant isoform expression. ${ }^{25}$ CD44 expression in non-Hodgkin's lymphoma is strongly associated with poor outcome, even in low grade lymphomas with small $S$ phase fractions. ${ }^{28}$ This is theoretically due to the ability of CD44 positive lymphoma cells to gain access to endothelial cells within lymph nodes and to disseminate subsequently. Conversely, the CD44 gene has been found to be downregulated in neuroblastoma cell lines. ${ }^{29}$

To date, several studies have reported the immunohistochemical expression of CD44 in carcinomas. Strong CD44 expression is associated with poor outcome in ductal carcinomas of the breast. ${ }^{30} \mathrm{~A}$ progressive increase in CD44 staining intensity was observed in gastric biopsy specimens progressing from normal to dysplasia to carcinoma, and appeared 
to be associated with poor outcome. ${ }^{31} \mathrm{By}$ contrast, in Barrett's oesophagus, strong CD44 staining was observed in non-dysplastic areas and was reduced in dysplasia and Barrett's associated adenocarcinomas. ${ }^{32}$ These studies offer contradictory or equivocal roles of CD44 in these gastrointestinal tumours.

More recently, Penno et $a l^{33}$ reported the results of their analysis of CD44 expression in lung tumours and lung tumour cell lines. CD44 expression was present in the majority of nonsmall cell carcinomas studied, but was absent in the majority of the small cell carcinomas. Reverse transcription and polymerase chain reaction (PCR) amplification determined that CD44S, but not the variant isoforms, was present in these tumours. No correlation was found between CD44 expression and tumour grade, stage or clinical outcome.

In the present study we investigated the cellular expression of total CD44 in T2N0 and T2N1 adenocarcinomas of the lung to determine whether any diagnostic or prognostic associations could be made in these tumours. Given the association of CD44 with tumour growth, ${ }^{18}$ large T2 tumours were chosen for study to determine specifically whether any difference in expression of CD44 was present in those surgically resectable tumours which developed nodal metastases and those that did not.

\begin{abstract}
Methods
Primary adenocarcinomas of the lung were sequentially selected from patients undergoing formal pulmonary resection between June 1981 and June 1991. Those patients from whom tissue blocks were not available were excluded. Tumours met pathological stage T2 criteria of tumour size greater than $3 \mathrm{~cm}$ located $2 \mathrm{~cm}$ or more distal to the carina, or of smaller size with visceral pleural invasion. ${ }^{34}$ Patients with metastases in ipsilateral peribronchial and/or ipsilateral hilar lymph nodes were classified as having N1 tumours. Patients with N2 and N3 disease, and metastasis to mediastinal, scalene or supraclavicular lymph nodes were excluded from this study. All patients were stable with less than $5 \%$ weight loss prior to surgery, and surgery was the primary and only treatment in this group. The pulmonary carcinomas were studied for histological grade (well, moderate or poorly differentiated), the presence or $a b$ -
\end{abstract}

Table 1 Clinical and pathological features of patient group

\begin{tabular}{lcc}
\hline Feature & $T 2 N O(n=16)$ & $T 2 N 1(n=15)$ \\
\hline Male/female & $11 / 5$ & $7 / 8$ \\
Age, mean (range) (years) & $64(51-90)$ & $59(37-80)$ \\
Tumour size, mean (range) (cm) & $4 \cdot 8(3 \cdot 3-6 \cdot 5)$ & $5 \cdot 0(3 \cdot 5-8)$ \\
Histological grade & 2 & 2 \\
$\quad$ well & 4 & 6 \\
moderate & 10 & 7 \\
poor & 6 & 4 \\
Pleural invasion & 10 & 13 \\
Angiolymphatic invasion & 4 & 2 \\
CD44 & 2 & 5 \\
$\quad$ negative & 6 & 2 \\
weak & 4 & 6 \\
moderate & 12 & 13 \\
strong & 48 & 23 \\
total & & \\
Median survival (months) & & \\
\hline
\end{tabular}

sence of angiolymphatic invasion, host inflammatory response (graded minimal, mild, moderate, or marked), pleural invasion, and nodal metastases.

\section{IMMUNOHISTOCHEMISTRY}

Immunoperoxidase staining was performed on formalin fixed, paraffin wax embedded sections of primary tumours and sections of lymph node metastases using the avidin-biotin complex technique as previously reported. ${ }^{35}$ Mouse antihuman monoclonal antibody $3 \mathrm{G} 12$ directed against CD44 (Dr G Dougherty), which recognises regions shared by all CD44 isoforms and is known to block CD44 mediated cellular adherence to hyaluronan, was run at a dilution of 1 in 5 . Antibodies which recognise specific variant isoforms are available; however, in our experience, adequate staining has not been obtained on archival formalin fixed, paraffin wax embedded sections, as used in this retrospective study. The secondary antibody consisted of biotinylated antimouse immunoglobulin (Vector, Burlingame, California, USA) at a dilution of 1 in 200. Slides were independently reviewed by three pathologists (MRC, DLC and SAY). Positive staining was graded on intensity $(1+$ to $2+$ ) and on percentage of positively staining cells $(1-24 \%, 25-49 \%, 50-74 \%$, and $75-$ $100 \%$, corresponding to $1+$ to $4+$ ). A combined score of 0 to 6 was assigned. Tumours which were scored at 0 to 1 were classified as negative; those as 2 were weakly positive; those as 3 and 4 moderately positive; and those as 5 and 6 strongly positive. Staining in nonneoplastic lung showed strong staining in the basal cells of the bronchial mucosa, and in lymphocytes and fibroblasts of the bronchial submucosa. These elements provided a positive internal control in sections with negatively staining tumours.

\section{STATISTICAL ANALYSIS}

Clinical follow up was obtained by review of medical records, tumour registry data and phone calls to patients and families. Statistical tests performed consisted of Student's $t$ test for continuous variables, Wilcoxon's rank sum test was used if the data were either skewed or variances were significantly different. The $\chi^{2}$ test was used for dichotomous variables and Fisher's exact test when expected frequencies were small. The Kaplan-Meier product-limit method of estimation was used to calculate survival curves. The log-rank test was used to test for differences in any survival curves constructed. Perioperative deaths were excluded from any analyses.

\section{Results}

Primary adenocarcinomas of the lung from 31 patients were studied. The clinical and pathological features are listed in table 1 . Twenty five $(81 \%)$ of the 31 tumours were CD44 positive with 18 showing moderate or strong staining. CD44 staining in tumours of low histological grade showed a distinct, basement 
Table 2 CD44 expression and tumour grade

\begin{tabular}{llcc}
\hline CD44 staining & \multicolumn{3}{l}{ Grade } \\
\hline Intensity & Well & Moderate & Poor \\
Negative & 0 & 2 & 4 \\
Weak & 2 & 1 & 4 \\
Moderate & 2 & 4 & 2 \\
Strong & 0 & 3 & 7 \\
Total & 4 & 10 & 17 \\
\hline
\end{tabular}

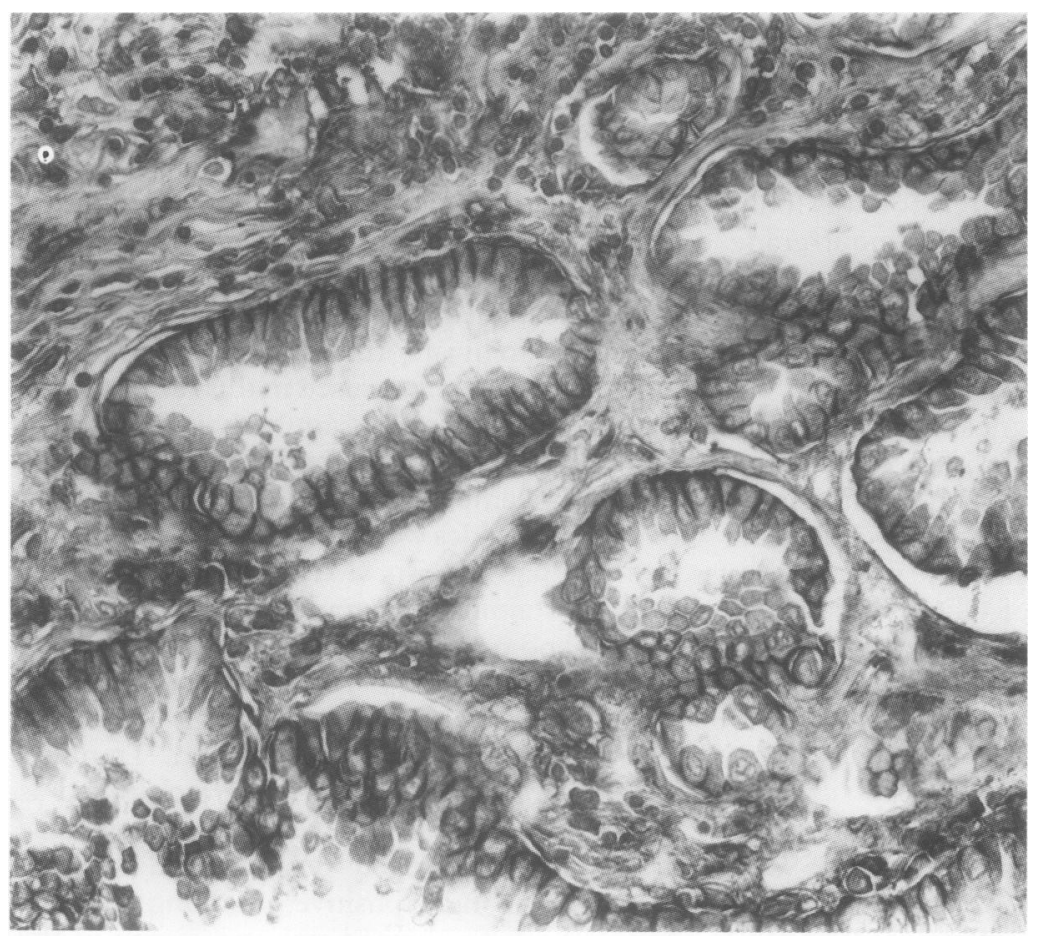

(A)

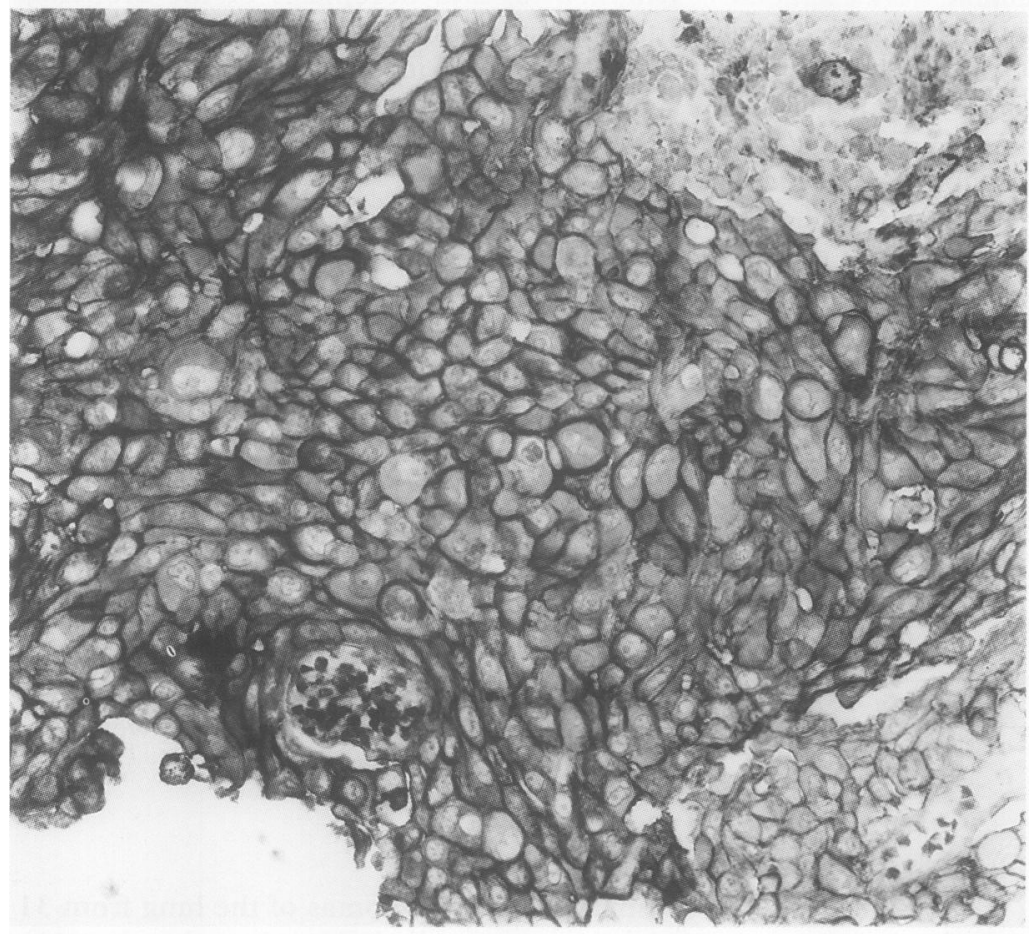

(B)

Figure 1 Immunohistochemical staining for CD44 in adenocarcinoma of the lung with monoclonal antibody $3 G 12$ which recognises the $N$ terminus which is not alternatively spliced. (A) Well differentiated adenocarcinoma showing lateral and basement membrane staining $(\times 200)$. $(B)$ Poorly differentiated adenocarcinoma with circumferential membranous staining $(\times 200)$. and lateral membrane pattern (fig $1 \mathrm{~A}$ ), whereas strongly positive high grade tumours demonstrated a circumferential membranous pattern (fig 1B). The staining pattern in nodal metastases paralleled that seen in the primary tumour, although it was generally weaker. CD44 expression correlated with tumour grade in that intense staining was seen only in grade 2 and 3 tumours (table 2); grade 1 tumours showed no or weak staining. A progressive increase from grade 1 to grade 3 was not present, however. No association was found between CD44 expression and pathological features, such as tumour size, pleural invasion, angiolymphatic invasion, degree of host inflammatory response, or tumour stage.

Excluding two perioperative deaths, long term follow up was available for 29 patients with a median survival of 48 months in the T1N0 group $(n=15)$ compared with 23 months for the T2N1 group $(n=14)$ ( $\mathrm{p}<0.07)$. In comparing CD44 expression with survival a positive association was observed, with a median survival of 46 months in the 16 patients (nine with $\mathrm{T} 2 \mathrm{~N} 0$ and seven with $\mathrm{T} 2 \mathrm{~N} 1$ disease) exhibiting moderate to strong expression compared with 24 months for the 13 patients (six with T2N0 and seven with T2N1 disease) with weak or no CD44 expression $(p<0.03)$ (fig 2). Nine patients were alive without evidence of disease at a median follow up of 61 months. Six $(40 \%)$ of the 15 patients with T2N0 and three $(27 \%)$ of those with T2N1 disease were in this group. Six $(66 \%)$ of these nine patients had strong CD44 expression, whereas strong expression was present in only three $(17 \%)$ of 17 patients dying with a median survival of 28 months $(p<0 \cdot 02)$.

\section{Discussion}

Molecular studies have demonstrated an association between CD44 expression and poor prognosis in lymphomas, and variant isoform expression and stage and outcome in breast and colon carcinomas. ${ }^{24-28}$ This has stimulated interest in the potential application of measurement of CD44 expression as a prognostic indicator in other epithelial malignancies. Antibodies which recognise total CD44 in fixed tissues, but not the variant isoforms, are available.

In this study of subgroups of stage I and stage II lung adenocarcinomas, total CD44 expression was as predictive of survival as conventional staging. Loss of CD44 in this group was associated with a worse outcome. This conflicts with preliminary reports of increased CD44 expression and poor outcome in ductal adenocarcinomas of the breast and adenocarcinomas of the stomach. ${ }^{3031}$ In breast tumours strong CD44 staining was more common in tumours of higher grade, as we observed, as well as in those with other aggressive histological features. In comparing mortality data on their patients with strong CD44 expression with those with weak expression, strong CD44 staining was associated with poor outcome in patients with ductal cancers and node positive cancers. No difference 


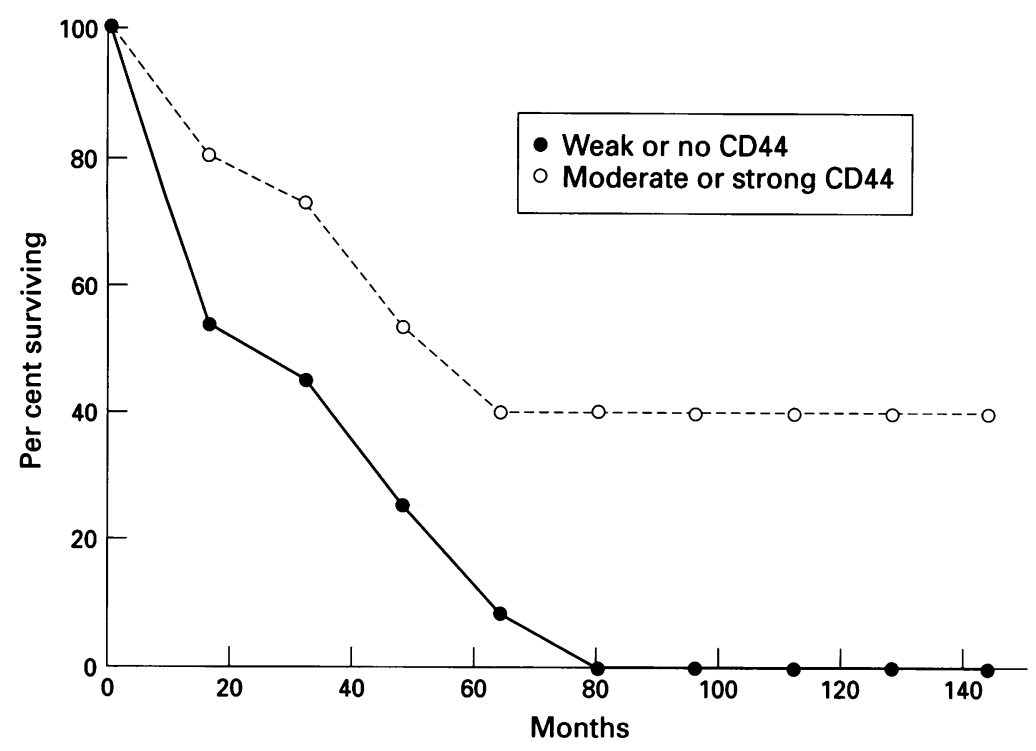

Figure 2 Kaplan-Meier analysis of patient survival and CD44 expression. A median survival of 46 months was observed for the $16(T 2 N 0=9 ; T 2 N 1=7)$ patients with moderate to strong cellular expression and 24 months for the 13 patients $(T 2 N O=6$; $T 2 N 1=7)$ with no or weak CD44 expression ( $p<0 \cdot 03)$ (log-rank test). was seen, however, in long term survival. Our findings do correlate with those observed in Barrett's dysplasia and Barrett's associated oesophageal adenocarcinomas, although clinical follow up was not available in that report. ${ }^{32}$ Also, in transitional cell carcinoma of the urinary bladder, loss of CD44 expression was seen in high grade tumours compared with low grade tumours and was also lost in aneuploid versus diploid tumours. ${ }^{36}$ In a recent preliminary study of lung tumours the presence of CD44 in nonsmall cell carcinomas and its virtual absence in the more aggressive small cell carcinomas suggested an inverse relation between CD44 and metastatic potential in lung tumours. ${ }^{33}$ The authors speculated that if CD44-hyaluronan interactions anchor cells in one area, the loss of hyaluronate binding capacity of cells lacking CD44 might relieve the cells of restraint to hyaluronate-rich tissue and facilitate metastatic spread. Furthermore, loss of the CD44R isoform, which is capable of forming dimers with both CD44S and CD44R molecules, may also act to promote loss of tumour cellular adherence, and thus tumour metastasis. ${ }^{37}$

In the present study associations cannot necessarily be made between total CD44 expression and variant expression. At this institution, preliminary studies on lung tumours and lung tumour cell lines using molecular techniques suggest that, unlike squamous cell carcinomas of the lung and adenocarcinomas from other sites, adenocarcinomas of the lung do not commonly express CD44v isoforms (D L Cooper, personal communication). Therefore, prognostic implications of CD44 expression in lung adenocarcinomas may relate more to loss of standard CD44, rather than acquisition of high molecular variants, as observed in other tumours. The loss of total CD44 expression in biologically aggressive tumours harkens to previous arguments that the defective binding of cells to the extracellular mat- rix permits increased mobility and metastatic potential in pulmonary adenocarcinomas. In invasion and metastasis models this loss of cell-cell adherence and cell-matrix adhesion facilitates cell mobility and spread. ${ }^{38}$ The results of this preliminary study provides support for this hypothesis.

The prognostic implications of total CD44 expression in lung tumours may be similar to that observed for cadherins, calcium dependent transmembrane cellular adhesion molecules also involved in homotypic cell-cell adhesion. ${ }^{38}$ Inhibition of cadherin mediated cellular adhesion was found to increase the invasive capacity of malignant epithelial cells. ${ }^{39}$ E-cadherin expression in breast and colon cancer has also been found to be inversely related to tumour grade. ${ }^{4041}$ Furthermore, in colonic carcinoma, loss of E-cadherin expression was significantly associated with lymph node metastases. ${ }^{41}$

Correlations between total CD44 expression and variant isoform expression and tumour stage, grade and patient outcome are not well understood, and may differ between different tissue types and organs. The findings in this study suggest that in primary adenocarcinoma of the lung total CD44 expression may have prognostic significance and as such, its determination may be a useful component of a prognostic panel of tests. Loss of CD44 expression in these tumours appears to correlate with more aggressive neoplasms, possibly due to loss of cell-cell or cell-matrix adhesion interactions mediated by this molecule.

1 Telan MJ, Eisenbarth GS, Haynes BF. Human erythrocyte antigens. Regulation of expression of a novel erythrocyte surface antigen by the inhibitor Lutheren $\operatorname{In}(\mathrm{Lu})$ gene. $\mathcal{F}$ Clin Invest 1983;71:1878-86.

2 Telen MJ, Palker TJ, Haynes BF. Human erythrocyte antigens: II. The IN(lu) gene regulates expression of an antigen on an 80-kilodalton protein of human erythrocytes. Blood 1984;64:599-606.

3 Jalkanen S, Steere AC, Fox RI, Butcher EC. A distinct endothelial cell recognition system that controls lympho-
cyte traffic into inflamed synovium. Science 1986;233: cyte trafic

4 Jalkanen S, Bargatze R, de los Toyos J, Butcher EC. Lymphocyte recognition of high endothelium: antibodies to distinct epitopes of an $85-95 \mathrm{kD}$ glycoprotein, antigen differentially inhibit lymphocyte binding to lymph node mucosal or synovial endothelial cells. F Cell Biol 1987;105:983-90.

5 Denning SM, Le PT, Singer KH, Haynes BF. Antibodies against the CD44 p80, lymphocyte homing receptor molecule augment human peripheral blood T cell activation. F Immunol 1990;144:7-15.

6 Huet S, Groux H, Caillou B, Valentin H, Prieur AM, Bernard A. CD44 contributes to $T$ cell activation. $\mathcal{f}$ Immunol 1989;143:798-801.

7 Belitsos PC, Hildreth JE, August JT. Homotypic cell aggregation induced by anti-CD44 (Pgp-1) monoclonal antibodies and related to CD44 (Pgp-1) expression. F Immunol 1990;144:1661-70.

8 Jalkanen S, Bargatze RF, Herron LR, Butcher EC. A lymphoid cell surface glycoprotein involved in endothelial cell recognition and lymphocyte homing in man. Eur $\mathcal{F}$ Immunol 1986;16:1195-202.

9 Wayner EA, Carter WG. Identification of multiple cell adhesion receptors for collagen and fibronectin in human fibrosarcoma cells possessing unique alpha and common fibrosarcoma cells possessing unique alpha and

10 Kalomiris EL, Bourguignon LYW. Mouse T lymphoma cells contain a transmembrane glycoprotein (gp85) that binds ankyrin. F Cell Biol 1988;106:319-48.

11 Jalkanen S, Jalkanen M. Lymphocyte CD44 binds the COOH-terminal heparin-binding domain of fibronectin f Cell Biol 1992;116:817-25.

12 Aruffo A, Stamenkovic I, Melnick M, Underhill CB, Seed B. CD44 is the principle cell surface receptor for hyaluronate. Cell 1990;61:1303-13.

13 Cooper DL, Dougherty G, Harn H-J, Jackson S, Baptist EW, Byers J, et al. The complex CD44 transcriptional unit; alternative splicing of three internal exons generates the epithelial form of CD44. Biochem Biophys Res Commun 1992;182:569-78.

14 Dougherty GJ, Lansdorp PM, Cooper DL, Humphries RK Molecular cloning of CD44R1 and CD44R2, two novel isoforms of the human CD44 lymphocyte "homing" re- 
ceptor expressed by hemopoietic cells. 7 Exp Med 1991; 174:1-5

15 Screaton GR, Bell MV, Jackson DG, Cornelis FB, Gerth U, Bell JI. Genomic structure of DNA encoding the lymphocyte homing receptor CD44 reveals at least 12 alternatively spliced exons. Immunology 1992;89:12160-4

16 Picker LJ, Nakache M, Butcher EC. Monoclonal antibodies to human lymphocyte homing receptors define a novel class of adhesion molecules on diverse cell types. $\mathcal{F} \mathrm{Cell}$ Biol 1989;109:927-37.

17 Thomas L, Byers HR, Vink J, Stamenkovic I. CD44H regulates tumor cell migration on hyaluronate-coated subregulates tumor cell migration on hyal
strate. $\mathcal{F}$ Cell Biol 1992;118:971-7.

18 Sy MS, Guo YJ, Stamenkovic I. Distinct effects of two CD44 isoforms on tumor growth in vivo. $\mathcal{f}$ Exp Med 1991. 174:859-66.

19 Stamenkovic I, Amiot M, Pesando JM, Seed B. A lymphocyte molecule implicated in lymph node homing is a member of the cartilage link protein family. Cell 1989;56 1057-62.

20 Gunthert U, Hofmann M, Rudy W, Reber S, Zoller M Haubmann I, et al. A new variant of glycoprotein CD44 confers metastatic potential to rat carcinoma cells. Cell 1991;65:13-24.

21 Rudy W, Hofmann M, Schwartz-Albiez R, Zoller M, Heider $\mathrm{K}-\mathrm{H}$, Ponta $\mathrm{H}$, et al. The two major CD44 protein $\mathrm{K}-\mathrm{H}$, Ponta $\mathrm{H}$, et al. The two major CD44 proteins
expressed on a metastatic rat tumor cell line are derived expressed on a metastatic rat tumor cell line are derived
from different splice variants: each one individually suffices from different splice variants: each one individually suffices

22 Hofmann M, Rudy W, Zoller M, Tolg C, Ponta H, Herrlich $\mathrm{P}$, et al. CD44 splice variants confer metastastic behavior in rats: homologous sequences are expressed in human tumor cell lines. Cancer Res 1991;51:5292-7.

23 Mackay CR, Terpe H-J, Stauder R, Marston WL, Stark H, Gunthert $U$. Expression and modulation of CD44 variant isoforms in humans. 7 Cell Biol 1994;124:71-82.

24 Heider K-H, Hofmann M, Hors, E, van den Berg F, Ponta $\mathrm{H}$, Herrlich $\mathrm{P}$, et al. A human homologue of the rat metastasis-associated variant of CD44 is expressed in colorectal carcinomas and adenomatous polyps. Am $\mathcal{F} \mathrm{Biol}$ 1993;120:227-33.

25 Finn L, Dougherty G, Finley G, Meisler A, Becich M, Cooper DL. Alternative splicing of CD44 pre-mRNA in human colorectal tumors. Biochem Biophys Res Commun 1994;200:1015-22.

26 Tanabe KK, Ellis LM, Saya H. Expression of CD44R1 adhesion molecule in colon carcinomas and metastases. Lancet 1993;341:725-6.

27 Matsumura Y, Tarin D. Significance of CD44 gene products for cancer diagnosis and disease evaluation. Lancet 1992; 340:1053-8.

28 Jalkanen S, Joensuu H, Soderstrom KO, Klemi PJ. Lymphocyte homing and clinical behavior of non Hodgkin's lymphoma. F Clin Invest 1991;87:1835-40.

29 Shtivelman E, Bishop JM. Expression of CD44 is repressed in neuroblastoma cells. Mol Cell Biol 1991;11:5446-53.

30 Joensuu H, Klemi PJ, Toikkanen S, Jalkanen S. Glycoprotein CD44 expression and its association with survival in breast cancer. Am ₹ Pathol 1993;143:867-74.

31 Washington MK, Gottfried MR, Telen MJ. Expression of the cell adhesion molecule CD44 in gastric adenocarcinomas [abstract]. Lab Invest 1993;68:52A

32 Moskaluk CA, Hamilton SR. Expression of CD44 in Barrett's esophagus and associated neoplasms [abstract]. Mod Pathol 1994;7:65A.

33 Penno MB, August JT, Baylin SB, Mabry M, Linnoila RI, Lee VS, et al. Expression of CD44 in human lung tumors. Cancer Res 1994;54:1381-7.

34 Beahrs OH, Henson DE, Hutter RVP, Kennedy BJ, eds. Manual for staging of cancer. 4th edn. Philadelphia: JB Lippincott, 1992:115-19.

35 Yousem SA, Ray L, Paradis IL, Dauber JA, Griffith BP. The role of dendritic cells in bronchiolitis obliterans in heart-lung transplantation. Ann Thorax Surg 1990;49:4248

36 del Rosario $\mathrm{AD}$, Bui $\mathrm{HX}$, Wu AS, Kin DN, Figge $H$, Fisher HAG, et al. CD44 and E-cadherin expression in transitional cell carcinoma of the urinary bladder [abstract]. Mod Pathol, 1994;7:73A

37 Dougherty GJ, Cooper DL, Memory JF, Chiu RK. Ligand binding specificity of alternatively spliced CD44 isoforms. Recognition and binding of hyaluronan by CD44R1. $f$ Biol Chem 1994;269:9074-8.

38 Albelda SM. Biology of disease: role of integrins and other cell adhesion molecules in tumor progression and metastasis. Lab Invest 1993;68:4-17.

39 Behrens J, Mareel MM, van Roy FM, Birchmeier W. Dissecting tumor cell invasion: epithelial cells acquire invasive secting tumor cell invasion: epithelial cells acquire invasive properties after the loss of uvomorulin-med
adhesion. $\mathcal{f}$ Cell Biol 1989;108:2435-47.

40 Gamallo C, Palacios J, Suarez A, Pizarro A, Navarro P, Quintanilla $\mathrm{M}$, et al. Correlation of E-cadherin expression with differentiation grade and histological type in breast carcinoma. Am $\mathcal{F}$ Pathol 1993;142:987-93.

41 Dorudi S, Sheffield JP, Poulsom R, Northover JMA, Hart IR. E-cadherin expression in colorectal cancer An immunocytochemical and in situ hybridization study. $\mathrm{Am} \mathcal{f}$ Pathol 1993;142:981-6. 